\title{
Determinants of Risk-Suitable Investment Portfolios: Evidence from A Sample of Italian Householders
}

\author{
Camilla Mazzoli ${ }^{*}$, Nicoletta Marinellib \\ aDepartment of Management, UniversitàPolitecnicadelle Marche, Ancona, Italy, \\ ${ }^{*}$ Corresponding author's email: c.mazzoli@univpm.it; Phone: +390712207254. \\ b Department of Economics and Law, Università di Macerata, Macerata, Italy. E-mail: \\ nicoletta.marinelli@unimc.it.c.mazzoli@univpm.it
}

H I G H L I G H T S:

1. The purpose of this paper is to understand how financial firms can improve a client's risk assessment by means of the MiFID suitability questionnaire.

2. We investigate the variables that intermediaries should take into account in the risk-holding and risk-allocation decision regarding single investors.

3. Heckit two-steps estimation is carried out on 1149 subjects interviewed in the 2008 Bank of Italy survey whose portfolios are risk-suitable.

4. A selective role of individual characteristics has been proven to exist when comparing risk-holding and risk-allocation decision.

5. 'Background' variables are to determine the risk-holding decision while the risk-allocation seems to be driven by a set of 'foreground' variables.

\section{Article History}

Received: 28-01-2014

Accepted: 25-02-2014

Keywords:

MiFID;

Investment portfolios;

Retail banking;

Risk profile;

Suitability.

JEL Classification:

G11; G21.
Available online: 28-02-2014

\begin{abstract}
According to the MiFID, financial intermediaries are requested to assess the suitability of the products they sell to retail clients. One of the main problems in the practical implementation of the MiFID suitability rule stems from omission or impreciseness of the questions specifically addressed to know the risk profile. Prompted by this evidence, the purpose of this paper is to shed light on the information an intermediary should collect in order to properly define a client's risk profile. We analyze a sample of 1149 subjects interviewed in the 2008 Bank of Italy survey whose portfolios are risk-suitable; then, we relate the portfolio risk composition to some characteristics of the owner. By using the Heckit two-steps estimation procedure we set apart the variables that mainly explain the risk-holding decision (whether to acquire risky assets) and the risk-allocation decision (how much to invest in risky assets). We find that the former is essentially related to a set of 'background' variables correlated with the capability of understanding and emotionally bearing the risk, while the latter depends on 'foregone' variables mainly related to the economic and financial capacity of each individual.
\end{abstract}

DOI: http://dx.doi.org/10.18533/jefs.v2i01.128

(C) 2014 The Authors. This is an open access article under the terms of the Creative Commons Attribution License 4.0, which allows use, distribution and reproduction in any medium, provided the original work is properly cited.

\subsection{Introduction}

Assessing suitability is an important Markets in Financial Instruments Directive (MiFID) requirement for investor protection, particularly in respect of retail clients. Accordingly, where the activities of an intermediary extend to specific advice or portfolio management services, investment firms must obtain the necessary information to understand the essential facts about the clients in order to ensure that the specific transaction recommended meets 
the client's characteristics and needs. The recent financial turmoil has even exacerbated structural problems stemming from poor advisory services and client's knowledge, as many retail investors have been found to have portfolios with a risk exposure that is not consistent with their effective risk profile. A study in Germany reports that clients end 50 to $80 \%$ of long-term investments prematurely because of unsuitable advice when buying financial products (Evers and Jung 2008). Moreover, recent data provided to the European Commission by the FINNET network reveal an alarming increase in the number of complaints relating to financial investment advice, especially in Italy, Ireland, France, and Belgium (European Commission 2011).

The growing concern regarding the quality and reliability of financial advice in the field of retail investments has also led international financial authorities to renew the debate about suitability. In July 2012, the European Securities and Markets Authorities (ESMA 2012) has published the final guidelines on certain aspects of the MiFID suitability requirements, after a consultation draft set out in December 2011, in order to enhance clarity and foster convergence in the implementation of the legislative prescriptions. In addition, the European Commission is working on a review of the first version of the MiFID framework and has also suggested using the MiFID suitability prescriptions as a benchmark for future regulation on the area of selling practices in the wider field of Packaged Retail Investments Products (PRIPs).

Recent evidence and supervisory experience (AMF 2011; European Commission 2011; FSA 2011) indicate that the main problems in the practical implementation of the MiFID suitability rule stems from three areas of deficiencies:

1. poor quality of MiFID suitability questionnaires, i.e. omission of questions or impreciseness of the questions asked which are relevant to know the customer's characteristics and needs;

2. poor quality of client profiles, i.e. inconsistency in the way the scores are assigned to the different variables in order to classify the client according to different categories;

3. poor quality of advisor's product recommendation, i.e. advisors may recommend products which are not in line with the client's profile.

Prompted by these evidences, this paper aims at contributing to the debate about the quality of the content of MiFID questionnaires actually used in order to assess the suitability of an investment product; this is, in a sense, the premise of the overall suitability process. Specifically, we try to understand what information an investment firm should collect from the customer in order to reach a comprehensive framework that allows to properly define the client's risk profile and therefore to propose a suitable portfolio with respect to this parameter. We confine our analysis to just one aspect of the MiFID suitability assessment that is the definition of the risk profile of the customer, as it has been found to be the most critical in practice and the trickiest to measure. Indeed, the FSA (FSA 2011) shows that of the 366 cases ranked as 'unsuitable' between March 2008 and September 2010, 199 are 'unsuitable' on the ground that investment selection failed to meet the risk a client is willing and able to take. In addition, the European Commission (European Commission 2011) underlines that the excessive risk investment accounted for over $80 \%$ of 'unsuitable' cases in Europe. For this reason, we are interested in understanding to what extent the MiFID questionnaires that are currently used by financial intermediaries can be improved in terms of the information that should be asked to clients when profiling their risk.

In order to estimate which variables should be taken into account for assessing the willingness and ability to take risk (risk profile), we analyze the financial decisions of the sample of Italian families subject to the 2008 investigation of the Bank of Italy Survey of Household Income and Wealth. Specifically, we analyze the decision of investing in risky assets among a subsample of 1149 subjects whose asset allocation may be considered risksuitable $^{1}$; then, we relate such a decision to the personal and family characteristics of the investor (sociodemographic characteristics, economic and financial situation, experience and knowledge, background risk) in order to derive which variables are more relevant in explaining a risky, but also suitable, financial behavior.

The novel contribution of our paper to the existing literature is twofold: first, academic research on individual financial behavior generally attempts to understand which factors determine individual evidence of investing in risky assets, without taking into account the 'suitability' or 'unsuitability' of such an investment decision in terms of risk. On the contrary, we restrict our analysis only to those subjects who may be supposed to hold risk-suitable portfolios, following a methodology already proposed by the financial risk tolerance literature to assess a valid risk profile of a subject. Secondly, our approach is based on the Heckit two-steps estimation procedure (Heckman 1979); apart from its pure technical advantage, this approach allows us to shed light on two different aspects of risk profile: the decision to acquire risky assets (risk-holding decision) and the decision about what fraction of wealth to invest in these assets (risk-allocation decision). These two aspects represent two different and subsequent stages in the process of knowing the client's risk profile, i.e. the holding decision firstly, and the allocation decision secondly.

\footnotetext{
1 The expression risk-suitable is used to restrict the term suitability just to the risk dimension. In other words it refers to the equivalence between the risk profile of the subject and the amount of risk he or she has in the portfolio; it does not consider the further suitability dimensions such the financial capability and experience and knowledge together with the other investment objectives items.
} 
Indeed, we assume that the variables influencing the first decision (risk-holding) are not necessarily the same that affect the second step of risk taking (risk-allocation).

The remainder of the paper is organised as follows: in Section 2 we describe the legislative background of our analysis and the results of previous studies in the field of MiFID suitability in Europe; in Sections 3 and 4 we discuss the data and methodology; the empirical analysis as far as the most relevant variables in defining the risk profile of a client is carried out in Section 5, while in Section 6 we check to what degree a sample of retail MiFID suitability questionnaires meets the variables we have previously found to be significant in the risk profiling of the client. Section 7 concludes.

\subsection{Background and previous studies}

The most recent and comprehensive legislative framework assessing the provision of advice to retail clients is provided by the Directive 2004/39/EC on markets in financial instruments (MiFID). This directive regulates the provision of investment services relating to financial instruments by investment firms and credit institutions. It sets a regulatory framework for safeguarding the interests of retail clients, whereby financial providers are required to act honestly, fairly and professionally in accordance with the best interests of their clients. Providers are also required, when offering the service of advice or portfolio management, to recommend investment products or services that are suitable for the client.Article 19 of the MiFID, as supplemented by the Implementing Directive 2006/73/CE, specifies the information that financial institutions are required to gather from their clients in order to define a suitable investment strategy that meets their characteristics and needs. This information relates to three main areas of knowledge about the client or potential client, specifically: the client's investment objectives, the client's financial capacity, the client's experience and knowledge.

Despite the explanations provided by the Implementing Directive, there is a considerable leeway for interpreting how these suitability requirements are to be implemented, particularly when it comes to the tools used to determine the client's risk profile. As a consequence, in the lack of a 'tight' benchmark to follow, each financial institution makes use of its own suitability questionnaire, that is designed for each specific situation and that is likely to be different from the ones used by its competitors.

On the investigation of suitability and its implementation in practice, supervisors have proved to be particularly active in order to raise the level of investor protection. Specifically, supervisors commissioned studies to examine whether current advisory practices across EU Member States are in line with the current legislative framework and to evaluate whether advisers provide suitable investment recommendations to retail clients (e.g. AMF, 2011; European Commission, 2011; FSA 2011). In this perspective, the occurrence of 'unsuitable' investment recommendations appears to be varied across EU Member States. It was generally observed that countries with especially high incidence of 'unsuitable' products recommendations tend to be the ones with more developed financial industries (for example, Denmark, 68\%; Finland, 56\%; Netherlands, 52\%; Sweden, 58\%; UK, 55\%; see European Commission 2011).

Where there is evidence of 'unsuitable' investment advice, these studies, in so far as this is possible, seek to identify and explain possible reasons behind recommendations of 'unsuitable' products. The studies focus on the following key areas: poor quality of MiFID suitability questionnaires; poor quality of client profiles; poor quality of advisor's product recommendation. As far as the quality of the MiFID questionnaire, on which this work concentrates, the studies outline the inaccurate understanding of the client's financial needs; this comes as consequence of an inaccurate content of the suitability questionnaire arising from omission of questions or impreciseness of the questions asked. In more details, specific problems include the following:

1. at the EU-level, it is observed that less than $10 \%$ of advisors adhere to all the general guidelines that are mapped under MiFID suitability requirements and the degree of compliance with the MiFID recommendations vary among countries and among financial firms within the same country (in this sense: European Commission, 2011; Marinelliand Mazzoli, 2011);

2. areas that seem to be most overlooked by advisors are the financial knowledge and investment experience of the clients as well as their financial capacity, as evidenced by the omission or the limited number of questions asked on these aspects. Generally, the questions deal more with experience than with knowledge (AMF, 2011); moreover, while aspects relating to the clients' personal income and assets are relatively better covered, advisors do not seem to gather adequate information about the clients' financial capacity, especially with regard to the clients' financial commitments, as well as other regular transactions or expenditures (AMF, 2011; Marinelli and Mazzoli, 2011);

3. although the clients' risk appetite appears to have been profiled by most advisors, the accuracy of questioning seems to be rather lacking for a significant number of advisors (AMF, 2011; Marinelli and Mazzoli, 2011). This suggests that advisors may have addressed MiFID's requirements on this aspects in a superficial way, since 
most do not seem to be very methodical or comprehensive in the manner in which they establish the client's profile or formulate the questions;

4. finally, there is a tendency for some advisors to overlook also the client's education level and profession (EU 2011; Marinelli and Mazzoli, 2011).This may pose a concern as some studies have indicated a possible linkage between education and financial capability with regards to choice of investment products (see, among others, FSA, 2006).

A common feature in the works cited above is that the analysis of questionnaire completeness is based solely on the MiFID general indications about the information to gather from the clients; in other terms, the approach of the previous studies is to evaluate how well each questionnaire complies with MiFID requirements about suitability, i.e. investment objectives, financial capacity, experience and knowledge. However, it is foreseeable that an advisor might have fulfilled all the required MiFID information from a question perspective and yet fails to arrive at a suitable recommendation; this does not suggest that the MiFID prescriptions are useless in preventing market failure, since adhering to such general guidelines helps at least to cover the baseline prerequisites for effective information gathering. Nonetheless, there are also some facts about the clients, not explicitly covered by the MiFID indications that might be informative about the level of risk an individual is willing and able to take. For example, the MiFID does not make questions about the client's socio-demographic characteristics mandatory, even if academic research (see, among others: Bertocchi et al., 2008; Cardak and Wilkins, 2009; Guiso et al., 2002) has shown that variables such as client's age, marital status, profession show correlation to investment objectives and are factor's in the client's risk profile.

In this sense, the present study tries to enrich the previous evidences on suitability by assessing the extent to which actual MiFID questionnaires comply not only with the 'text' of the MiFID but with the 'spirit' of the underlying law as well - that is the effective knowledge of the client risk profile in order to recommend risk-suitable investment strategies.

\subsection{Selection of the sample and variables}

We select within the sample used in the 2008 Bank of Italy survey a sub-sample made only by the householder of the families that were interviewed. The survey reports a definition of the householder as 'the person who is responsible for the financial and economic choices of the household'; therefore, our selection of the sub-sample comes from the assumption that the family investment decision are likely to be taken by the householder and, as a consequence, the portfolio composition depends on his or her personal characteristics together with the economic and financial situation of the family. This restriction gives rise to a sample of 7977 subjects, instead of the 19907 interviewed in the 2008 Bank of Italy survey. We then propose a selection criterion in order to include within the sample only the householders' portfolios that are to be considered as risk-suitable.

In this perspective, we first deepen the connection between risk profile and financial risk tolerance (FRT). The definition of financial risk tolerance is inherently context dependent: a first definition applies to an operational context, in terms of financial advising and can be defined as the risk profile of the client. The second is where risk tolerance is defined as a construct by economists and behavioral psychologists. The third is a regulatory definition, which stems from recent reform to the financial industry authorities (Subedar 2007) ${ }^{2}$.Despite the different terms that are used, all of the three expressions lead back to the FRT of the subject, that is the risk that he or she is willing and able to take depending on his or her risk attitude, risk knowledge, risk propensity and risk capacity (Cordell 2001).

In time, the literature has proposed a multitude of possible tools to measure the FRT (Rozokowski and Grable 2005) ${ }^{3}$. The most common methods are:

1. Interviews, where the subject is requested to self-assess his or her FRT;

2. Analysis of portfolio composition, that is the effective investment behavior;

3. Psychometric questionnaires, where the subject gives responses to hypothetical situations of financial risk (sometimes under the lottery form).

Nevertheless, each of the above mentioned approaches has its proponents and detractors (Rozokowski and Grable, $2005)^{4}$. Therefore, averaging the answers from different techniques should prove to be the most 'valid' approach

\footnotetext{
${ }^{2}$ This is the risk profile as included into the investment objectives of the MiFID questionnaires. See Marinelli and Mazzoli (2011) for a detailed analysis of the difference between risk profile and risk preference in the MiFID regulatory provisions.

${ }^{3}$ See also Callan and Johnson 2002; Hallahan, Faff and McKenzie 2004; Hanna and Chen 1977; Hanna, Gutter and Fan 2001; MacCrimmon, Wehrung and Stanbury 1986; Roszkowski 1992.
} 
because some approaches may overestimate the true level of risk tolerance whereas others may underestimate it. So far, we propose a way to select a sample of subjects whose risk profile can be considered 'valid' according to the averaging methodology proposed by Rozokowki (1992).

We first consider questions C36 of the Bank of Italy Survey where subjects are requested to self-assess their FRT in terms of the amount of risk they are willing to bear in a financial situation.

We then analyze the portfolio composition by calculating the percentage of risky assets included in each householder's portfolio in 2008.In order to group the assets into some risky categories, we follow the methodology already used by Brunetti and Torricelli $(2010)^{5}$ thus setting apart:

1. Safe assets: current accounts, saving deposits, postal deposits, certificate of deposits and cooperative loans;

2. Fairly safe assets: postal bonds, short and term government bonds, bonds, repo, investment funds, personal asset management, pension funds, Life insurances, Health-insurances, other insurances;

3. Risky assets: corporate bonds, stocks, SRL shares, partnerships, foreign assets.

4. The total portfolio risk is measured by the weighted sum of the risky assets included in the portfolio where the weights applied are: 0 to the safe assets, $50 \%$ to the fairly safe assets and $100 \%$ to the risky assets.

Finally, we consider question R2.14 as a hypothetical risk situation experiment ${ }^{6}$. Nevertheless, the R2.14 answer is available only for 4090 subjects and, so far, it cuts our sample from 7977 to 4090 . In order to select the 'valid' portfolios according to the averaging methodology suggested by Rozokowki (1992) we need to set apart subjects that exhibit a consistent risk profile across all of the three FRT measures. To do this, we compute the average score obtained in each of the three measures by all of the sample and we keep only the subjects that have all of the three scores consistent (all of them above, below or equal to the average of the sample). The sample is thus reduced to 1149.

\subsection{Dependent variables}

Starting from the information about the 2008 portfolio composition, we build the dependent variables involved in the Heckit two-steps estimation procedure. Specifically, we derive the dependent variable of the first step by linking to each subject in the sample a dummy variable Risk-Holding $(\mathrm{RH})$ whose value is 0 if no risky asset is included in the portfolio and 1 if any risky asset is involved. The first step of the model should give information about the variables to be taken into account when choosing if risky assets are suitable for a specific investor.

The same information is used to build the dependent variable of the second step of the model. In particular, we build the variable Risk-Allocation (RA) that is the percentage of risky assets that is included into the portfolio following the distinction between risky and not risky assets already illustrated above. The equation of the model is expected to inform on the variables that must be taken into account when deciding how much risk is suitable for a specific investor.

\subsection{Independent variables}

For each householder, the survey provides plenty of both personal and family information, of which we have used those belonging to the following categories: socio-demographic (SD), background risk (BR), knowledge and experience (KE), economic and financial situation (EFS).The detailed construction of the independent variables is presented in the appendix 01 .

Note that table 01 in appendix illustrates the single independent variables that are involved into the model, the category each variable belongs to, the label and the typology of variable. All the data are collected from the 2008 Bank of Italy Survey of Household Income and Wealth. In particular, the financial literacy variable comes from questions C.47 and C.48 of the Bank of Italy Survey. In both the questions we assign a score equal to 1 to the first possible answer (the right one) and a score 0 to the remaining ones. We then sum the scores of each question, thus obtaining a range from 0 (no answer is right) to 2 (both answers are right).

\footnotetext{
${ }^{4}$ In particular the self-assessed FRT could be biased by how the subject perceives himself or herself with respect to propensity for risk; the portfolio composition could be strongly influenced by economics and financial constraints or by the current market situation and it could also be fail in informing about one's willingness to change the actual composition. Finally, the psychometric questionnaires, while relevant for giving sound financial advice, are not really part of the psychological construct of risk tolerance per se and are too short to be valid for assessing individual subjects (Roszkowski, Davey and Grable 2005).

${ }^{5}$ The authors use a risk classification that is based on the joint consideration of credit risk and market risk; as for the latter, three main forms are considered, i.e. exchange rate risk, interest rate risk and price risk. Still, they skip some other forms of risk such as liquidity risk because of the lack of information in the Bank of Italy Survey and we are forced to do the same.

${ }^{6}$ Question R2.14 refers to a time choice more than to a risk choice; nevertheless, part of the literature maintains that risk and time affect choices via a common underlying dimension; therefore, delaying an outcome is equivalent to making it risky (Epper and Fehr-Duda 2013; Keren and Roelofsma 1995; Weber and Chapman 2005).
} 
As we already pointed out above, some of the variables that we consider into our model are also included into the MiFID provisions and some others are innovative of our model. More specifically, the first two categories of variables (socio-demographic and background risk) are not included into the MiFID but are likely to influence the risk profile of an investors. For example, with reference to the socio-demographic variables, previous studies take into account the relationship between age and risk propensity and also between gender and marital status and risk propensity. With reference to age, previous studies show that risk tolerance tends to decrease with age (see Ameriks and Zeldes, 2004; Brandt, 2010; Gollier, 2002). For this reason, we split the variable age into 4 ranges $\left(\mathrm{AGE}_{1}, \mathrm{AGE}_{2}, \mathrm{AGE}_{3}\right.$ and $\left.\mathrm{AGE}_{4}\right)$ in order to better understand which age range is likely to be featured by a higher risk or lower propensity. With reference to gender (GEN) and marital status (MAR), Dohmen et al. (2005), Hinz et al. (1997) and Lusardi and Mitchell (2008) find that women generally reveal a higher degree of risk aversion if compared to men. Moreover, Lupton and Smith (2003) and Waite and Gallagher (2000) demonstrate that the marital status is positively linked to risk perception, as marriage seems to play a sort of financial security over subjects.

As far as background risk, it was initially formalized by Pratt and Zeckhauser (1987);specifically, background risk is associated with a number of factors supposed to increase an individual's situation of uncertainty, such as labor income uncertainty, proprietary income and housing (e.g. Guiso et al., 1996; Heaton and Lucas, 2000; Shum and Faig, 2006).These predictions have led to empirical studies aimed at assessing the role of background risk in the portfolio allocation of households (see, for example: Cardak and Wilkins, (2009). We include three proxies for background risk in the regression model: employment risk is captured with a dummy variable that equals 1 if the individual is employed (EMPL); volatility of future labor income is expressed by a variable describing the type of employment and distinguishing between those who are employees (highly predictable income) as opposed to selfemployed (potentially higher, but less certain income) (EMPL_STAT); finally, we construct another dummy variable as proxy for proprietary real estate (HOUSE) that equals 1 if the subject has a proprietary house and 0 otherwise. The remaining categories, that are experience and knowledge and economic and financial situation, are also included into the MiFID provisions.

We do not include variables such as C36 (self-assessment of FRT) and R2.14 (hypothetical risk situation) into the model because, despite they help in drawing the FRT of each subject involved, they are our sample selection criterion; therefore, we expect them to be always extremely significant and positively related to the portfolio risk by definition.

\subsection{The model}

Analytically, the Heckit two-steps estimation procedure is:

$$
\left.\begin{array}{l}
R H^{*}{ }_{i}=z_{i}^{\prime} \gamma+u_{i} \\
R A_{i}=x_{i}^{\prime} \beta+\varepsilon_{i} \quad \Leftrightarrow R H^{*}{ }_{i}>0
\end{array}\right\}
$$

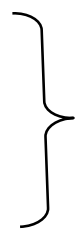

Where, $i$ is the sample size from 1 to 1149.

The first equation is the selection equation, where $z_{i}^{\prime}$ is a group of 10 variables belonging to the four categories illustrated in appendix which determine the decision to take risk, measured by a latent variable $R H^{*}{ }_{i}(R i s k$ Holding); $\gamma$ is a vector of coefficients which reflects the effect of these variables on the risk-holding decision and $u_{i}$ is the random error term. The latent variable $R H^{*}{ }_{i}$ is not observed; a dichotomic variable $R H_{i}$ which is positive if the considered portfolio contains at least one risky asset is observed instead. The 10 variables included into the first equation mainly belong to the socio-demographic and background risk categories; in fact, we hypothesize that the $\mathrm{RH}$ decision might be mainly driven by a set of 'background variables' that influence the emotional attitude of the householder towards taking risk. In this sense, we suppose that the specific variables about the economic and financial situation of the householder are not heavily involved into this first decision about risk but they are likely to influence more deeply the second step of the decision.

The second equation of the system is the $R A$ (Risk-Allocation) equation which is the linear model of interest; the vector $x_{i}^{\prime}$ contains 7 explanatory variables which determine the percentage of risky assets held in the 2008 portfolios, $\beta$ is a vector of coefficients which reflects the effect of these variables on the risk-allocation decision and $\varepsilon_{i}$ is the random error term. In this second equation we assume that the RA decision is mainly driven by a set of 'foreground variables' which focus on the capacity of the householders to financially bear risk. In brief, following the distinction already proposed by Cordell (2002), we hypothesize that the RH decision is mainly driven by risk 
attitude (the amount of risk one chooses to incur), while the RA decision depends on the risk capacity (how much risk one can afford to incur) of the householder.

\subsection{Empirical results}

Model 01 is estimated by Maximum Likelihood (ML), which jointly returns the estimates of both the RH and RA equation and guarantees consistency and asymptotic normal efficiency (see for example: Greene, 1981). The estimation results are provided in Table 02, while Table 03 contains the regression statistics; all the results are confirmed by a battery of preliminary estimates that were conducted to check the robustness of the model ${ }^{7}$.

A potential drawback of the Heckit model is that estimates are generally inconsistent if the normality assumption of selection equation residuals fails (Pagan and Vella, 1989). In order to control for a correct specification of the model, we carry out a Conditional Moment (CM) test for normality, where the asymptotic distribution is the standard chi-square. Additionally, the Heckit model may suffer from some problems of collinearity (Puhani, 2000) that may vanish the credibility of the estimates; hence, we test for collinearity among variables by calculating the variance inflation factor (VIF) for each of the regression coefficients, where the upper limit generally recommended is 10 (Neter et al., 1985).

\begin{tabular}{|c|c|c|c|c|c|c|}
\hline \multicolumn{7}{|c|}{ Table 02: Heckit estimation: risk-holding and risk-allocation equation } \\
\hline \multirow[t]{2}{*}{ Variable } & \multicolumn{3}{|c|}{ Risk-Holding } & \multicolumn{3}{|c|}{ Risk-Allocation } \\
\hline & Coeff. & s.e. & p-value & Coeff. & s.e. & p-value \\
\hline Const & -2.1284 & 0.2036 & $0.0000^{* * *}$ & 0.4022 & 0.0432 & $0.0000 * * *$ \\
\hline \multicolumn{7}{|l|}{ SD } \\
\hline $\mathrm{AGE}_{1}$ & 0.1213 & 0.1580 & 0.4426 & & & \\
\hline $\mathrm{AGE}_{3}$ & -0.1416 & 0.1290 & 0.2723 & & & \\
\hline $\mathrm{AGE}_{4}$ & -0.5398 & 0.1717 & $0.0017^{* * *}$ & & & \\
\hline MAR & 0.3349 & 0.0985 & $0.0007^{* * *}$ & & & \\
\hline GEN & 0.1029 & 0.0976 & 0.2916 & & & \\
\hline \multicolumn{7}{|l|}{$\mathrm{BR}$} \\
\hline EMPL & -0.2780 & 0.1660 & $0.0940 *$ & & & \\
\hline EMPL_STAT & -0.1579 & 0.1493 & 0.2901 & & & \\
\hline HOUSE & 0.4820 & 0.1029 & $0.0000^{* * *}$ & & & \\
\hline \multicolumn{7}{|l|}{$\mathrm{KE}$} \\
\hline FIN_LIT & 0.4830 & 0.0516 & $0.0000 * * *$ & & & \\
\hline \multicolumn{7}{|l|}{ EFS } \\
\hline DEPEND & & & & -0.0138 & 0.0113 & 0.2206 \\
\hline MORTG & & & & $1.53 \mathrm{e}-07$ & $4.39 \mathrm{e}-07$ & 0.7268 \\
\hline WEALTH & & & & $1.32 \mathrm{e}-08$ & $2.13 e-08$ & 0.5346 \\
\hline GEN_COND & 0.3709 & 0.0396 & $0.0000 * * *$ & & & \\
\hline INCOME & & & & $1.23 \mathrm{e}-06$ & $4.29 \mathrm{e}-07$ & $0.0043^{* * *}$ \\
\hline CONS_CRED & & & & $-5.32 \mathrm{e}-06$ & $1.03 e-05$ & 0.6051 \\
\hline OVER_AM & & & & $5.08 \mathrm{e}-06$ & $5.07 \mathrm{e}-06$ & 0.3165 \\
\hline OTHER_FIN & & & & $-5.98 e-07$ & $2.85 e-07$ & $0.0360^{* *}$ \\
\hline lambda & & & & -0.1425 & 0.0255 & $0.0000 * * *$ \\
\hline \multicolumn{7}{|c|}{$\begin{array}{l}\text { Note: Table } 02 \text { presents the results of the Heckit estimation where the dependent variable is: } 1 \text { ) in the first step (Risk-Holding equation), a } \\
\text { dummy variable which is } 1 \text { if the considered portfolio contains at least one risky asset, and } 0 \text { otherwise; } 2 \text { ) in the second step (Risk- } \\
\text { Allocation decision), a quantitative variable which indicates the percentage of risky assets held in the } 2008 \text { portfolio. The columns report the } \\
\text { coefficient, the robust standard error and p-value for each variable. We refer to Table } 01 \text { for a detailed description of each explanatory } \\
\text { variable. } \\
{ }^{*} \text { Significance at } 1 \% \text { level; }{ }^{* *} \text { Significance at } 5 \% \text { level; }{ }^{* *} \text { Significance at } 10 \% \text { level } \\
\text { The reference variable for the AGE set of dummies is AGE } 2\end{array}$} \\
\hline
\end{tabular}

Finally, we calculate the condition number (CN), where a $\mathrm{CN}>30$ indicates problems of collinearity (Belsley et al., 1980). The results of these specification controls make us confident that the selection problem was satisfactorily dealt with: the null hypothesis of the CM test is accepted and both VIF and CM test are below the cut off figures recommended.

Table 03: Regression statistics

$\begin{array}{ll}\text { Mean of dependent variable } & 0.3331 \\ \text { Std.dev. of dependent variable } & 0.2603\end{array}$

\footnotetext{
${ }^{7}$ All the preliminary estimates are omitted for conciseness, but are available upon request from the authors.In particular; the Heckit model was estimated also considering different combinations of the explanatory variables to be included in the first and second step of the estimation. However, these estimates led to a worse specification of the model.
} 


\begin{tabular}{ll}
\hline Total observations & 1,149 \\
Censored observations (\%) & $688(59.9 \%)$ \\
Sigma & 0.2661 \\
Rho & -0.5358 \\
Log likelihood & -570.6491 \\
Akaike Information Criterion & $1,159.298$ \\
Schwarz Information Criterion & $1,196.499$ \\
No. cases correctly predicted & $862(75 \%)$ \\
\hline Note: Table 03 presents the regression statistics for the Heckit estimation where the dependent variable is: \\
1) in the first step (Risk-Holding equation), a dummy variable which is 1 if the considered portfolio contains \\
at least one risky asset, and 0 otherwise; 2) in the second step (Risk-Allocation decision), a quantitative \\
variable which indicates the percentage of risky assets held in the 2008 portfolio.
\end{tabular}

\subsection{Effects of estimated variables on the probability of holding risky assets}

This section discusses the results for the first step of the Heckit model aimed at investigating which characteristics of an individual are more likely to predict the ownership of risky assets. This may help to define a preliminary threshold in the risk profiles graduation, separating the totally conservative risk profile from the others.

The relationship between age and the risky asset ownership fits the traditional form which is often assumed in the studies of risky asset holdings: based on the life-cycle hypothesis, most papers (see Ameriks and Zeldes, 2004; Brandt, 2010; Gollier, 2002) suggest that the propensity to invest in risky assets should decrease with age, a rule that has been often suggested by professional consultants too (Malkiel, 1996) as the (100 minus age)\% rule. As Ardehali (2005) points out, this observation is justified by a standard discounting perspective: younger investors have a greater number of years to recover from any possible losses, hence they are more likely to incur with risky investments. Other studies develop the idea of a hump-shaped curve; with a peak in the middle age and a decline later (see Benzoni et al., 2007; Brunetti and Torricelli, 2010). Accordingly, we obtain a significant and negative coefficient for older individuals $\left(\mathrm{AGE}_{4}\right)$, however neither prime-age $\left(\mathrm{AGE}_{1}\right)$ nor third-age $\left(\mathrm{AGE}_{3}\right)$ investors show significant coefficients. The last result may be partly explained by considering that what really matters is not just the age of the subject, but rather the increased knowledge of the investment landscape and opportunities that come with experience, as outlined by Bertaut (1998), Cardak and Wilkins (2009) and King and Leape (1987). So far, the effect of the above mentioned variables could be hidden under more meaningful variables such as the financial education. In line with this interpretation, we find that the likelihood of risky asset holding increases with a greater level of financial education (FIN_LIT): these results are consistent with holdings being strongly affected by knowledge and financial literacy, as discussed by Bertocchi et al. (2008), Campbell (2006), Cardak and Wilkins (2009), Grable and Joo (2000), Guiso et al. (2002) and Van Rooij at al. (2007) and highlights the importance of being able to understand financial institutions and markets as a determinant of household's decision to invest in risky assets.

In line with a strand of literature focusing on the impact of marital status on financial choices (e.g. Bertocchi et al., 2011, Lupon and Smith, 2003), civil status (MAR) is found to have an influence: married individuals are more incline to invest in risky assets than singles. As suggested by Bertocchi et al. (2011), the difference between married and single individuals can indeed be attributed to the idea of marriage as a source of financial security, hence, to the value of marriage as a sort of "safe asset" when making financial risk-holding decisions. In line with the findings of Grable and Joo (1999) and Hanna et al. (1998), gender differences (GEN) do not affect the probability of investing in risky assets, contrary to the common belief that females are more risk averse than males (see, among others: Eckel and Grossman, 2008; Fellner and Maciejovsky, 2007; Hartog et al., 2002 and Powell and Ansic, 1997). Clearly, differences of gender are not indicative by themselves of the propensity to invest in risky assets, but rather related to different underlying risk propensity or economic condition that determines the ownership decision. Bertocchi et al. (2011) find that the general tendency to the emancipation of all women in the last decades causes a continuing increase in female labour participation, as well as an increase in women's economic stability and ability to make financial decision; this may result in a convergence of women to the same risk behaviour than men, thus justifying the statistical irrelevance of the gender coefficient. This interpretation seems to be further confirmed by our results, where "background variables" such as employment status (UNEMPLOYED), house ownership (HOUSE) and general economic conditions (GEN_COND) play a decisive role in the decision to hold risky assets and may possibly capture the gender effect more directly. Households that are unemployed have a lower probability of holding risky assets, which can be explained by the fact that bearing labour risk can reduce the propensity to participate in risky financial decisions; the variables measuring the general economic condition of the family and house ownership are both strongly significant and positive.

\subsection{Effects of estimated variables on the share of wealth allocated in risky assets}


The second step of the Heckit model allows us to discuss, conditional on owning some risky assets, which variables are relevant to predict a greater share of financial wealth into these assets. This is a sort of second risk threshold, which enables to graduate different level of risk, farther and farther from the totally conservative profile. Also these empirical results are summarized in Table 02.

Overall, we find that few variables, among those observed, are able to influence the risk-allocation decision. Among the variables capturing the presence of family ties and financial constraints, only OTHER_FIN is significant, with a negative sign as expected: individuals who have more debt constraints, other than mortgage expenses tied to the primary residence, tend to have less risky assets in their financial portfolio. As Faff et al. (2003) find, the number of family members is not significantly related to the share of wealth allocated in risky assets. This result may be justified by considering that what really matter is not just the family composition, but rather the economic capacity to support dependents and make financial investments. In line with this argument, the amount of income (INCOME) positively influences the percentage of risky assets in portfolio: individuals with higher level of income display a higher portion of the portfolio invested in risky assets. This evidence has also an interpretation in terms of participation costs: as Guiso et al. (2002) observe, in the presence of participation costs, the investors perceive a net benefit from being in the market if the potential amount to be invested in risky assets is sufficiently large. Moreover, the financial services sector often offer better terms to large investors than to smaller ones, further amplifying the relevance of income. On the opposite, the net amount of wealth (WEALTH) is not a significant variable in determining the risk allocation decision. As Ardehali (2005) discusses, one can hypothesize that a wealthier person can more easily afford to incur the losses resulting from a risky investment; however, it is also plausible that wealthy people are more worried about losing their fortune or, alternatively, people with a lower level of personal wealth are more likely to bet on their future. Empirical works support these opposite arguments: Bertocchi et al. (2008) and Cardak and Wilkins (2009) find that individuals with higher level of net wealth display a higher portion of the portfolio invested in risky assets; conversely, Bluethgen et al. (2008) obtain the opposite result, supporting the hypothesis of an Increasing Relative Risk Aversion (IRRA) where the risk aversion of an individual increases with wealth. Our seemingly counter-intuitive finding about the statistical irrelevance of wealth is therefore in line with the less clear effect of this variable on risky asset holding.

Finally, it should be noted that results reported in Table 02 also show that the coefficient for lambda is statistically significant. This indicates that a sample selection mechanism is indeed operating and thus that the Heckit model is superior to OLS. The fact that this coefficient is also negative suggests that the two stages of the portfolio decision decision to hold risky assets and decision about the amount of risky assets - are negatively correlated, revealing generalised conservatory risk behaviour in our sample of Italian families, as also reported in BorsaItaliana (2012).

To summarize, the decision to hold risky assets seems to be driven by a different sample of variables compared to the risk allocation decision; specifically, the ownership decision in the first step may be inferred by a set of "background" variables that essentially express the capability of the subject to understand and psychologically bear the risk (financial education and background risk, that may induce a greater sense of uncertainty), obviously controlling for the economic stability of the individual. However, in the first step a synthetic indicator of general economic condition is sufficient to derive consistent results together with information about house ownership. The following decision about the share of risky assets seems to be harder to predict as already maintained by Guiso et al. (2002). Moreover, it is induced by a different set of variables including specific indicators of the financial and economic power of the subject ("foreground variables"). Using the language of Cordell (2002) we might say that the ownership decision is essentially a 'risk attitude' decision, whilst the allocation decision is more a 'risk capacity' decision.

\subsection{Analysis on a sample of suitability questionnaires}

The empirical analysis we carried out up to now helps us to identify which information financial firms should collect from their customers in order to perform a good risk profiling process. Yet, at this stage of the analysis, it is also interesting to investigate to what degree financial intermediaries are aware of the importance of the single items we have found to be essential in the risk profiling of the customer. In other terms, we are now interested in identifying which of the above mentioned variables financial firms do insert in the suitability questionnaires they submit to their clients before providing them with financial advisory or portfolio management. To carry out such an analysis, we collected a sample of 25 questionnaires addressed to retail clients; all of the questionnaires belong to the major Italian financial groups but, in order to respect applicable privacy laws, we are forced to skip their names. The analysis takes into account the presence of both the variables that are crucial in the assessment of the risk-holding decision and of the variables involved in the risk-allocation choice, although separately. Table 04 is referred to both the first phase and the second step of the analysis.

At a first glance, table 04 shows that financial firms seems to be scarcely aware of the main variables that should be taken into account when assessing the opportunity of providing a client with financial risk. In particular, the 64\% 
pays attention to how clients consider their economic condition (GEN_COND) (with questions such as 'Do you make use of your investments return to cover current expenses as your income flow is not sufficient on the purpose?') even if little attention is dedicated to other important economic variables such as the house ownership (HOUSE) $(16 \%)$.

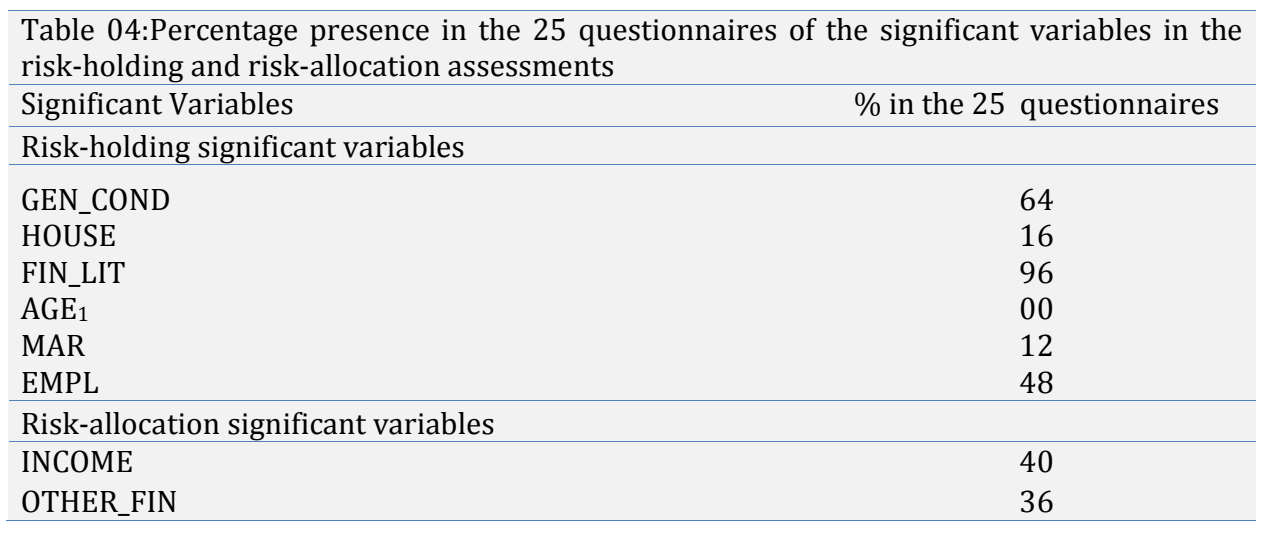

to education, shows that a

high
financial firms ask customers questions about their financial education (FIN_LIT) (96\%). Still, despite a high percentage of firms investigating the financial education level, most of the times, clients are requested to declare how educated they think to be, thus giving rise to answers that can be biased by the self evaluation of the subject. In fact, some questions are asked as a confirmation of the answer, such as 'Are you aware that stocks are more risky than bonds?'. Other times, the question is placed as 'How would you define your financial knowledge' or 'Tick the box if you know the financial instrument'. This way, financial firm cannot be sure of the real financial education of the subject and seems to be more interested in being compliant with the law than understanding the financial education of the client.

An evident flaw is related to the age variable $\left(\mathrm{AGE}_{1}\right)$; in fact, despite it is considered highly important in the literature about risk tolerance and also significant in our model, all the 25 MiFID questionnaires completely ignore the age of the subjects thus failing to acquire other important information in the $\mathrm{RH}$ assessment ${ }^{8}$. As far as the marital status (MAR), only the $12 \%$ of the financial firms in the sample considers this information as relevant and the $48 \%$ of the sample asks questions about the employment status (EMPL) of the client.

With reference to the second phase of the analysis, i.e. the variables involved into the risk-allocation decision, some problems emerge in terms of the variables that are used in order to understand how much risk to give to a client. The economic and financial variables we have found to be crucial are ignored by more than a half of the financial firms in the sample; in particular, only the $40 \%$ deepens the knowledge of the regular income of the client and the $36 \%$ asks questions about the financial commitments other than mortgages.

Some problems referred to the risk tolerance measurement also emerge. We already stressed in the previous paragraphs the importance of comparing alternative measures of financial risk tolerance to assess a valid risk profile of the client, as suggested by Roszkowski (1992). So far, we deepened how and how often the financial risk tolerance is investigated in the 25 questionnaires. Surprisingly, a high percentage of firms focus on the risk attitude of the client (96\%). In fact, due to the difficulty in assessing the risk attitude of a subject, one might hypothesize that this item is not always taken into account in the risk profiling of a client. Nevertheless, the high percentage of firms investigating the risk attitude can be better explained by going deeper into the questions that are generally asked with reference to this topic. Most of the financial firms in the sample seem to be only interested in the level of risk the client declares to desire in terms of general purpose of his or her investments. In particular, the client is often asked about his or her preferences in respect of the financial risk-return combination of future investments; conversely, the attitude of the client towards a general situation of riskiness or uncertainty is rarely comprised. This gives rise to a well know problem (Marinelli and Mazzoli, 2011) about the misrepresentation of the risk attitude of the client.

\subsection{Concluding remarks}

The theme of suitability is extremely relevant as it involves both the interests coming from single intermediaries that offer investment services and from the authorities in terms of the investors' protection. In particular, knowing a customer is crucial to intermediaries for two main reasons: in the production process, information about clients help intermediaries to design products and services which can be specifically marketed and sold to particular

\footnotetext{
${ }^{8}$ Truthfully, financial intermediaries can collect information about age from other sources such as the clients database; nevertheless, the few scoring systems we had the opportunity to look up do not include the variable age in the score.
} 
segments of customers; in the distribution process, they make use of the information they collected from clients in order to provide them with products and services that are suitable to their profile. A good assessment of a client's risk profile prevents intermediaries from two possible mistakes; if they give to a client a profile that undervalues the risk he or she really can bear, the customer could not be totally satisfied with the low return of the investments. Even worst, by overvaluing the profile, a customer could be given too much risk compared to the level of risk he or she can really bear or wishes and this is likely to raise conflicts between intermediaries and clients.

Suitability also has important implications in terms of protecting both the investor and the intermediary. In fact, the information that is obtained from the customer in the profiling process is crucial in each step of the contract: before the financial service or product is subscribed, in order to meet the preferences and needs of the investors and provide them with products that are suitable to their personal and economic characteristics(thus protecting them from an inappropriate portfolio allocation); during the contract, in order to acquire any changes in the needs and preferences of the investor that could require changes in the portfolio composition and after the end of the contract, in order to protect the intermediary against any complaint that the client could make with reference to a loss that he or she did not expect but is physiological according to the level of risk that characterizes the investment.

The Market in Financial Instruments Directive imposes the practice of profiling customers to financial firms that provide investment services; specifically, the MiFID requires investment firms to assess the suitability and appropriateness of any product or service before it is offered to clients. In other words, the intermediary is requested to test if the client has the necessary knowledge and expertise, together with the financial capacity and the right investment objectives, to trade in financial instruments and to understand the risks associated with this trading activity. In practice, the above mentioned suitability assessment is performed by making use of a questionnaire whose function is twofold: on the one hand, it should allow intermediaries to better know their clients and, on the other hand, it is expected to reduce any possible misunderstandings, thus protecting financial firms against complaints.

Notwithstanding the effort of the European Authorities in promoting a better knowledge of investors among intermediaries, recent evidence and supervisory experience has shown that questionnaires that are currently used by financial firms tend to be inefficient in assessing the suitability of financial products and services. In particular, the main problems stem from the risk profile. In fact, the information that is currently requested into the MiFID questionnaires may be not completely adequate to understand the level and typology of risk an investor is willing and able to bear. In this sense, this paper contributes to the debate about the quality of the content of MiFID suitability questionnaires for retail clients by shedding light on the variables that a financial firm should properly take into account both in the risk-holding and risk-allocation decision regarding single investors. To do this, we analyze the financial decisions of a sample of Italian families subject to the 2008 investigation of the Bank of Italy Survey of Household Income and Wealth; in particular, we analyze the decision of investing in risky assets among a subsample of subjects whose asset allocation may be considered risk-suitable and we relate such a decision to some characteristics of the investor (socio-demographic characteristics, economic and financial situation, experience and knowledge, background risk).

First of all, our work highlights the importance of using alternative measures to detect the FRT of a subject and to verify the consistency between the relative scores; in our sample, only $28 \%$ percent of individuals are consistent among the three measures of FRT as derived from the Bank of Italy Survey. This reveals that in the remaining $72 \%$ of cases there is some inconsistency between the effective investment behavior and the self-assessed attitude toward risk. Understanding the reasons underlying this inconsistency paves the way for future research.

Furthermore, the results confirm our main hypothesis in that the 'background variables' (financial education and background risk) are to determine the risk-holding decision conditioned by the economic stability of the individual, while the risk-allocation seems to be driven by a set of 'foreground variables'depicting more in depth the financial and economic strength of the subject. We also find the allocation harder to predict than the holding decision.

In order to understand to what degree the financial firms take into account the above mentioned variables we carry out an analysis on a sample of 25 Italian MiFID suitability questionnaires addressed to retail clients. As expected, some problems emerge as many important variables in both the risk-holding and risk-allocation decision are almost ignored: less than half of the sample includes questions about age, proprietary house, civil and employment status, regular income and financial constraints of the subject. Some other variables, despite their substantial presence, are misplaced. In particular, the financial education and the risk tolerance are present in the $96 \%$ of the cases but the way the questions are placed cannot grant a reliable profiling of the client.

In light of the recent worldwide financial turbulence, we believe the above mentioned issues to be urgently addressed. The financial crisis has revealed not only the shortcomings of the international financial system but also the limits of the tools that are currently being used by financial intermediaries to profile investors and thus 
properly advise them accordingly. This seems to be the appropriate time to deal with these issues provided that, in Europe, suitability and appropriateness obligations have been in effect for years.

To conclude, much work remains to do in order to improve the quality of the current suitability questionnaires in terms of a better assessment of the risk profile of the clients. In particular, financial authorities are expected to assist financial firms by suggesting improvements that could reduce the incompleteness and impreciseness of the information that are currently collected in the risk profile assessment of clients. Furthermore, the evidences we provided pave the way for a debate about the opportunity for the European Regulator to impose a single and standardized format for the questionnaire. On the one hand, such a questionnaire could solve the actual weaknesses with reference to the incompleteness and impreciseness of the information required; however, on the other hand, this may contrast with the need for intermediaries to fit the questionnaire on their business model.

Future developments of this study will be addressed to enlarge the study to an international perspective in order to highlight if and how the variables we have found to be significant for the Italian sample are fully applicable to other geographical clusters. Moreover, other interesting areas of research also need to be explored; a promising area of study comes from the scores that intermediaries use in order to weight each question within the suitability questionnaire. In fact, despite the items that are include into the questionnaires represent the first step towards a good risk assessment, the risk profile also derives from the scores that are assigned to each of items but, on this point, financial authorities have not imposed nor suggested any particular methodology thus paving the way for a wide variety of scoring methods across firms.

\section{References}

Ameriks J., Zeldes S., 2004. How do household portfolio shares vary with age? Working Paper. Columbia Business School.

AMF, 2011. Evaluation of MiFID questionnaires in France. http://www.amf-france.org/en_US/Publications/Rapportsetudes-et-analyses/Epargne-et-prestataires.html

Ardehali PH, 2005. Assessing financial tolerance of portfolio investors using data envelopment analysis. PhD Thesis. University of Toronto, Centre for Management of Technology and Entrepreneurship.

Bertaut C.C., 1998. Stockholdings behavior of US households: evidence from the 1983-1989 survey of consumer finances. The review of Economics and Statistics, 80:263-275.

Bertocchi G., Brunetti M., Torricelli C., 2008. Portfolio choices, gender and marital status. Rivista di Politica Economica, 985:119-154.

Bertocchi G., Brunetti M., Torricelli C., 2011. Marriage and other risky assets: a portfolio approach. Journal of Banking and Finance, 35: 2902-2915.

Belsley DA, Kuh E, Welsch RE, 1980. Regression diagnostics: identifying influential data and sources of collinearity. New York: John Wiley.

Benzoni L., Collin-Dufresnem P., GoldsteinR.S., 2007. Portfolio choice over the life-cycle when stock and labour markets are cointegrated. Journal of Finance, 62:2123-2167.

Bluethgen R., Gintschel A., Hackethal A., Muller A., 2008. Financial advice and individual investors' portfolios. Working Paper, European Business School.

Borsaltaliana, 2012. Rapport osullo shareholding e il trading on line in Italia.http://www.borsaitaliana.it/borsaitaliana/ufficiostampa/comunicati-stampa/2012/tolexpo2012ilrapportodiborsaitalianasuazionariatoetradingonline_pdf.htm

Brandt, M.W., 2010. Portfolio choice problems, in: Ait-Sahalia,Y., Hansen, L.P. (Eds.), Handbook of financial econometrics.Elsevier Science, Amsterdam,pp.269-336.

Brunetti M., Torricelli C.,2010. Population age and household portfolio choices in Italy. European Journal of Finance, 16(6):481-502.

Callan V.J., Johnson M., 2002. Some guidelines for financial planners in measuring and advising clients about their levels of risk tolerance. Journal of Personal Finance, 11:31-44.

Campbell J.Y., 2006. Household finance. Journal of Finance, 61:1553-1604.

Cardak B.A., Wilkins R., 2009. The determinants of household risky asset holdings: Australian evidence on background risk and other factors. Journal of Banking and Finance, 33:850-860.

Cordell D.M., 2001. RiskPACK: how to evaluate risk tolerance. Journal of Financial Planning, 14(6): 36-40.

Cordell D.M., 2002. Risk tolerance in two dimensions. Journal of Financial Planning, 15(5): 30-33.

Dohmen T., Falk A., Huffman D., Sunde U., SchuppJ., Wagner G.G.,2005. Individual Risk Attitudes: New Evidence from a Large, Representative, Experimentally-Validated Survey. IZA Discussion Paper 1730.

Eckel C.C., Grossman P.J., 2008. Forecasting risk attitudes: An experimental study using actual and forecast gamble choices. Journal of Economic Behavior and Organization, 681:1-17.

Epper T., Fehr-Duda H., 2013. The missing link: Unifying Risk Taking and Time Discounting. Working Paper 096. University of Zurich,.

ESMA, 2012. Guidelines on certain aspects of the MiFID suitability requirements. Consultation Paper. http://www.esma.europa.eu/consultation/Consultation-paper-guidelines-certain-aspects-MiFID-suitability-requirements 
European Commission, 2011. Consumer market study on advice within the area of retail investment services. Final Report. http://ec.europa.eu/consumers/rights/docs/investment_advice_study_en.pdf

Evers and Jung, 2008. Anforderungen an Finanzvermittler. Launched by the German Consumer Affairs Ministry. http://www.bmelv.de/cae/servlet/contentblob/379922/publicationFile/21929/StudieFinanzvermittler.pdf

Faff R.W., Hallahan T., McKenzie M.D., 2004. An empirical investigation of personal financial risk tolerance. Financial Services Review, 13(1): 57-78.

Fellner G., Maciejovsky B., 2007. Risk attitude and market behavior: Evidence from experimental asset markets.Journal of Economic Psychology, 283: 338-350.

FSA, 2006. Levels of Financial Capability in the UK. Results of a baseline survey. http://www.fsa.gov.uk/pubs/consumer-research/crpr47.pdf

FSA, 2011. Assessing suitability: establishing the risk a customer is willing and able to take and making a suitable investment selection. Guidance Consultation. http://www.fsa.gov.uk/pubs/guidance/gc11_01.pdf

Gollier C., 2002. What does theory have to say about household portfolios?, in: Guiso, L., Haliassos, M., Jappelli, T. (Eds.), Household Portfolios. MIT Press, Cambridge, pp. 27-54.

Grable J.E., Joo S., 1999. Factors related to risk tolerance: a further examination. Consumer Interests Annual, 45: 5358.

Grable J.E., Joo S., 2000. A cross-disciplinary examination of financial risk tolerance. Consumer Interests Annual, 46: 151-157.

Greene W.H., 1981. Sample selection bias as a specification error. Econometrica, 49: 795-798.

Guiso L., Haliassos M., Jappelli T., 2002. Household stockholding in Europe: where do we stand and where do we go? Discussion paper, 2002-09.

Guiso L., Jappelli T., Terlizzese D., 1996. Income risk, borrowing constraints, and portfolio choice. American Economic Review, 86: 159-172.

Hallahan T.A., Faff R.W., McKenzie M.D., 2004. An empirical investigation of personal financial risk tolerance.Financial Services Review, 13:57-78.

Hanna S.D., Chen P., 1997. Subjective and objective risk tolerance: Implications for optimal portfolios. Financial Counseling and Planning, 82: 17-26.

Hanna S.D., Gutter M.S., Fan J.X., 1998. A theory based measure of risk tolerance. Proceedings of the Academy of Financial Services, 10-11.

Hanna S.D., Gutter M.S., Fan J.X., 2001. A measure of risk tolerance based on economic theory. Financial Counseling and Planning, 122: 54-60.

Hartog J., Ferrier-CarbonellA., Jonker N., 2002. Linking measured risk aversion to individual characteristics. Kyklos, 551: 3-26.

Heaton J., Lucas D., 2000. Portfolio choice and asset prices: the importance of entrepreneurial risk. Journal of Finance, 55:1163-1198.

Heckman J., 1979. Sample selection bias as a specification error. Econometrica, 47:153-161.

Hinz R.P., Mccarthy D.O., Turner J.A., 1997. Are Women Conservative Investors? Gender Differences in ParticipantDirected Pension Investments. Pension Research Council Working Paper 9617, University of Pennsylvania.

Keren G., Roelofsma P., 1995. Immediacy and certainty in intertemporal choice. Organizational Behavior and Human Decision Processes, 63:287-297.

King M.A.,Leape J.I.,1987. Asset accumulation, information, and the life cycle. NBER Working Paper, 2392.

Lupton J.P., Smith J.P., 2003. Marriage, assets and savings, in: Grossbard-Shecht, S. (Ed.), Marriage and the Economy: Theory and Evidence from Advanced Industrial Societies. University Press, Cambridge, pp. 129-152.

Lusardi A., Mitchell O.S., 2008. Planning and financial literacy: How do women fare?.American Economic Review, 98: 413-417.

MacCrimmon KR, Wehrung DA, Stanbury WT, 1986. Taking risks. New York: The Free Press.

Malkiel BG,1996. A random walk down wall street, including a life-cycle guide to personal investing. New York: W.W. Norton \& Company.

Marinelli N., Mazzoli C., 2011. The traditional approach to risk tolerance, in: Lucarelli C., Brighetti, G. (Eds.), Risk tolerance in financial decision making. Basingstoke: Palgrave Macmillan Studies in Banking and Financial Institutions, pp. 81-112.

Neter J, Wasserusan W, Kutner M, 1985. Applied Linear Statistical Models: Regression Analysis of Variance and Experimental Design. Boston: Irwin.

Pagan A., Vella F., 1989. Diagnostic tests for models based on individual data: A survey. Journal of Applied Econometrics, 4:29-59.

Powell M., Ansic D., 1997. Gender differences in risk behavior in financial decision making: An experimental analysis. Journal of Economic Psychology, 186:605-628.

Pratt J., Zeckhauser R., 1987. Proper risk aversion. Econometrica. 551: 143-154.

Puhani P.A., 2000. The Heckman correction for sample selection and its critique. Journal of Economic Survey, 14(1):53-68.

Roszkowski M.J., 1992. How to assess a client's financial risk tolerance: the basics, in: Mawr, B. (Ed.), Personal financial risk tolerance. PA: The American College, pp. 66-75. 
Roszkowski M.J., DaveyG. , Grable J., 2005. Insights from psychology and psychometrics on measuring risk tolerance.The Journal of Financial Planning, 184:66-75.

Roszkowski M.J., Grable J., 2005. Estimating Risk Tolerance: The Degree of Accuracy and the Paramorphic Representations of the Estimate.Financial Counseling and Planning, 162:29-47.

Shum P., Faig M., 2006. What explains household stock holding?. Journal of Banking and Finance, 30: 2579-2597.

Subedar Z, 2007. Evaluation of subjective risk tolerance categorization methods used by financial advisors: evidence from a psychometric financial risk tolerance questionnaire. PhD Thesis. University of Wollongong, School of Accounting.

Van Rooij M., Lusardi A., Alessie R., 2007. Financial literacy and stock market participation. NBER Working Paper, 13565.

Waite L, Gallagher M, 2000. The Case for Marriage: Why Married People are Happier, Healthier, and Better off Financially. New York: Doubleday.

Weber B. J., Chapman G.B., 2005. The combined effects of risk and time on choice: Does uncertainty eliminate the immediacy effect? Does delay eliminate the certainty effect?', Organizational Behavior and Human Decision Processes, 96:104-118.

\section{Appendix 01:}

Table 01: List of independent variables involved into the model

\begin{tabular}{clll}
\hline Category & Variable & Label & Typology \\
\hline SD & Age up to 37 & AGE 1 & dummy: 1 if yes \\
SD & Age from 38 to 57 & AGE2 & dummy: 1 if yes \\
SD & Age from 58 to 77 & AGE 3 & dummy: 1 if yes \\
SD & Age more than 78 & AGE 4 & dummy: 1 if yes \\
SD & Marital status & MAR & dummy: 1 if married \\
SD & Gender & GEN & dummy: 1 if man \\
BR & Unemployed & EMPL & dummy: 1 if yes \\
BR & Type of employment status & EMPL_STAT & dummy: 1 if employee \\
BR & House ownership & HOUSE & dummy: 1 if yes \\
KE & Financial literacy & FIN_LIT & scale: 0 low, 2 high \\
EFS & Number of dependents & DEPEND & number \\
EFS & Mortgage & MORTG & amount \\
EFS & Household wealth & WEALTH & amount \\
EFS & General economic condition of the & GEN_COND & scale: 1 very bad, 6 very good \\
& family & & \\
EFS & Household income & INCOME & amount \\
EFS & Consumer credit installment & CONS_CRED & amount \\
EFS & Amount of overdrawn & OVER_AM & amount \\
EFS & Other financings & OTHER_FIN & amount
\end{tabular}

